Case Report

\title{
Ethical and Legal Considerations for Collection Development, Exhibition and Research at Museums Victoria
}

\author{
Nancy Ladas \\ Museums Victoria, Melbourne 3000, Australia; nladas@museum.vic.gov.au \\ Received: 31 January 2019; Accepted: 8 March 2019; Published: 13 March 2019
}

\begin{abstract}
With over 17 million collection items, Museums Victoria is the largest museum in Australia. Museums Victoria recognises the public benefit derived from lending and borrowing between collecting institutions and actively participates in the international loans network in order to complement and enhance the potential for learning and enjoyment for all audiences. Museums Victoria staff undertook an extensive review of policies and procedures in order to apply for approval for protection under the Australian Government's Protection of Cultural Objects on Loan Scheme (PCOL Scheme), established to administer the Commonwealth Protection of Cultural Objects on Loan Act 2013 (PCOL Act). The PCOL Scheme provides (with some limits) legal protection-immunity from seizure-for Australian and foreign cultural items on loan from overseas lenders for temporary public exhibition in Australia. The Ministry for the Arts also released the Australian Best Practice Guide to Collecting Cultural Material in 2015. The Guide is not a mandatory code. It recommends principles and standards to apply when acquiring collection items and in part for inward and outward loans. In 2016-2017 Museums Victoria staff used the Act and its Regulation along with the Guide to substantially update and formalise previous formal and informal policies and practices, in order to demonstrate its commitment to due diligence endeavours to verify the accuracy of information before acquiring, deaccessioning, borrowing, or lending items. This paper outlines the steps we took and what we have learned since receiving approval as a registered borrower under the PCOL Scheme.
\end{abstract}

Keywords: collections; due diligence; provenance; immunity from seizure; Australia; museum

\section{Introduction}

Australia is a big continent and an increasingly significant player in the international movement of contemporary, historical, and scientific collections for exhibition and research, both incoming and outgoing.

Our First Peoples possess and nurture the oldest continuous living culture in the world. Our antipodean landscapes and waters sustain unique fauna and flora and our people, of varying descent, lead and foster technological innovations, art forms, fashion, music, and culinary tastes.

My foray into international loans started in 2004 as the assistant producer of the museum's 150th anniversary celebrations. We borrowed, for temporary exhibition in the Etched on Bark 1854: Kulin barks from Northern Victoria display, three Aboriginal bark etchings from the British Museum and the Royal Botanic Gardens, Kew. It was the first time I had engaged in the process of borrowing items from overseas. It would be the first time these items would return to Australia and be within the reach of the Dja Dja Warrung land and people.

The senior curator at the time, Elizabeth Willis, liaised with local community representatives in Australia and colleagues in the United Kingdom. The loan agreement was drafted, exchanged for each party to agree and sign, and the items despatched to Melbourne Museum for installation. 
The exhibition opened on 18 March 2004. Six weeks after the exhibition opened Gary Murray, a leader of the Dja Dja Wurrung, a member of the museum's Aboriginal Cultural Heritage Advisory Committee and also Chair of the North West Regional Aboriginal Cultural Heritage Board, 'called for the Prime Minister to ask the British Government to return the bark etchings to Australia permanently' [1].

An Emergency Declaration on behalf of the Elders of the Traditional Owners was lodged under 'Subsection 21C Emergency declaration of preservation of the Aboriginal and Torres Strait Islander Heritage Protection Act 1984' (a federal statute) on 18 June 2004 (Federal Court of Australia 20 May $2005,4)$. The declaration was 'intended to protect and preserve the three cultural heritage objects from further threats of injury and desecration' [2]. The effect was to prevent the re-export of the barks, for an initial period of 44 days. When the first declaration expired, a further seven were made, one almost every 30 days. The items were no longer on display and remained in Melbourne beyond the terms of the agreements.

This was problematic for Museums Victoria (MV). If the items were returned, we would break Australian law and destroy imperfect, but long-established, relationships with the community. If the items were not returned MV would dishonor the agreements with the lenders. Internationally the event jeopardised the legal framework of borrowing and lending for all museums " I can understand the motivation of people in Australia in trying to seize the items, but it adds to the difficulty of international lending generally," Maurice Davies, deputy director of the Museums Association, which represents Britain's 1500 public collections, told the (Times) newspaper' [3]. All parties involved agreed to extend the loan period while negotiations took place. The Museums Board of Victoria sought a review of each emergency declaration and the injunctions were dissolved and the items eventually returned to the lenders.

\section{Museums Victoria}

MV's origins date back to 1854, with the founding of the National Museum of Victoria and the establishment, in 1870, of the Industrial and Technological Museum of Victoria. By proclamation of the Victorian Museums Act 1983, these two institutions were amalgamated to form what is known today as Museums Victoria, governed by the Museums Board of Victoria. We are not the oldest museum in Australia, but our collections are the most varied.

We have been developing the State collections for over 160 years and offer them for use in exhibitions and research, and build our education and public programs around them. MV has developed some of the most significant collections of Australian Indigenous cultural material in the world, extensive natural sciences collections with a particular strength in material from South-Eastern Australia and surrounding waters, and a unique collection representing Victoria's historical and technological developments. The estimated size of the collection is 17.1 million items, of which about 1.9 million registration units, of about 4.2 million, are registered in the electronic collection management database.

We have three sites offering exhibitions, education and public programs and one offsite collection stores. We are the custodian of the Royal Exhibition Building, the site of the opening of the first Federal Parliament on 9 May 1901 and inscribed on the UNESCO World Heritage List on 1 July 2004 [4]. And, in September 2018, we had just over 500 ongoing, casual, and fixed term staff, and hundreds of tertiary students and volunteers.

\section{Institutional Buy-In}

In 2011 MV responded to the Australian Government discussion paper on Immunity from Seizure for Cultural Objects on Loan [5] an investigation into the lack of 'comprehensive immunity from seizure legislation in place which protects objects from seizure whilst on loan to collecting institutions.' The discussion paper summarised the current state of play for the Australian collecting sector in negotiating loans with lenders and widely-held concerns about the lack of robustness of 'letters of comfort' and the increasing call for immunity guarantees from overseas lenders. At the time protection 
from seizure could be sought in limited and quite specific purposes under the Commonwealth Protection of Movable Cultural Heritage Act 1986 and the Foreign State Immunities Act 1985. MV also contributed to the response from the Council of Australasian Museum Directors (CAMD) [6], as did the ICOM Australia Executive, of which I was an Ordinary Member at the time.

The Protection of Cultural Objects on Loan Bill 2012 (the Bill) provided for the establishment of the PCOL Scheme to provide protection for cultural objects on loan and was introduced and read on 28 November 2012 and assented on 14 March 2013. As the Hon Simon Crean MP, noted at the time of its introduction it would 'align Australia with an emerging international standard of providing protection for cultural objects on loan from overseas' and 'reassure foreign lenders that Australia is a secure destination for loans' [7].

The PCOL Act protects cultural objects from legal proceedings while they are on temporary exhibition in Australia, often referred to as 'immunity from seizure and suit' [8]. Eligible Australian borrowing institutions, of which MV is one, can voluntarily apply for a five-year approval period under the PCOL Scheme. The decision to approve a borrowing institution, or not, is based on a rigorous assessment of the suitability of its policies and procedures. Once protection is granted objects imported for temporary exhibition in Australia are automatically protected for a maximum of two years from the date of their importation. An application to extend can be made in exceptional circumstances.

The PCOL Scheme is the result of comprehensive consultation with the collecting sector and places Australian public galleries, libraries, and museums in a stronger position to negotiate the loan of items from overseas lenders. The Australian Government announced that the Scheme was open for applications in February 2015. MV did not have any upcoming international exhibitions and there was not an urgency to act which meant that we were able to watch and learn, with much interest, the application process undertaken by other organisations. The first organisation to receive protection was the National Gallery of Victoria, Melbourne.

We commenced the process by formally advising the museum's Executive Management Team of the new legislation, the Protection of Cultural Objects on Loan Act 2013, and its implications for existing processes and thinking. We sought executive buy-in to undertake the review and their support to allow staff from across the organisation to contribute. We needed to understand and account for the explicit legislative requirements to undertake and document due diligence, provenance research, and consultation in order to borrow items from overseas for temporary display. We also alerted them to changes in decision-making and reporting obligations based on their roles and financial delegation.

While the specific trigger for the review were the PCOL Act, the PCOL Scheme and the Guide, we also wanted to take into account other new, related frameworks, including:

- the ICOM Code of Ethics for Natural History Museums, 2013

- the Nagoya Protocol on Access to Genetic Resources and the Fair and Equitable Sharing of Benefits Arising from their Utilization (ABS) to the Convention on Biological Diversity came into force in 2014.

The Museums Board of Victoria had recently approved the Repatriation of Indigenous Cultural Property Policy in 2015 and the policies listed below in 2013 with a proposed review cycle of five years:

- Collection Access, Loans and Use

- Collection Care and Preservation

- Collection Deaccession

- Collection Development.

For approval, the federal government needs to be satisfied with an organisation's governance, policies, processes, training, and associated frameworks for collection practice, including acquisition, lending and borrowing. There are certain absolute requirements in the new legislation with preferred emphases relating to the management of incoming international loans for temporary exhibition. There were also preferred requirements and emphases for broader approaches to collection 
development, borrowing and lending, embodied in the Ministry for the Arts Australian Best Practice Guide to Collecting Cultural Material.

A central tenet of these new frameworks is that the institution undertakes and documents due diligence in order to warrant the accuracy of ethical provenance trails and legal title before deciding on a course of action such as acquisition or loan. MV has established a risk-based approach to this requirement in the revised policies. Moreover, the PCOL Scheme and the Guide place special emphases on consulting communities of interest, and especially Indigenous communities, in the proposed collection actions.

We consulted with the administrators of the PCOL Scheme in the Ministry for the Arts before and during our review and received several rounds of feedback, the last of which indicated that they thought our policies were of a high quality.

The first thing we did was summarise the Museum's existing policy and procedural framework alongside the PCOL Scheme and the Guide. We also looked at what our colleagues in PCOL-registered museums and galleries had used as evidence in their successful approval. Our existing policies and procedures provided the beginning of the evidence we needed as part of the application. However, there were gaps. With these identified we formed a core group of three staff, drafted a schedule of tasks and dates and discussed the skills required to form the Ethical and Legal Collecting and Lending (ECLC) working group. We were looking for staff who would engage with the review and who would actively advocate and communicate the findings and the outcomes of the application process and changes to process to their staff and teams.

\subsection{Ethical Collecting and Legal Collecting Working Group}

We held our first meeting on 10 February 2016. We discussed the timeframe and our goal was to complete the review with the creation of new and modifications to existing documents in order to submit an application for protection under the PCOL legislation by May 2016. We decided to apply the Act, Regulation, and Guide more broadly to acquisition, deaccession (and repatriation), as well as inward and outward loans for exhibition and research.

We split the ECLC working group into sub-groups and called in other staff for specific principles and processes. For example we discussed the Collection Provenance and Legal Title Enquiries and Claims Policy and Procedure with the front-of-house public information team. This team manages all incoming requests for information, complaints and positive feedback in a database and they are responsible for directing claims and enquiries to the relevant curatorial or exhibition staff. We also needed a dedicated page to summarise the Scheme and outline the enquiries and claims process, as well as 'publish' all items proposed for loan prior to their export to Australia for temporary exhibition, and so we also consulted with MV's web team.

At the beginning of April we reviewed the timeframe and extended our deadline to August. This was largely to account for sign-off by sub-committees of the Museums Board of Victoria-we needed to seek approval from the Aboriginal Cultural Heritage Advisory Committee, the Research Committee, and the Finance, Audit, and Risk Committee.

In May 2016, we submitted a summary of the proposed policy structure (see Table 1) with a brief commentary on the extent of revision to the Executive Management Team and a suggested approach for the associated procedures. 
Table 1. Museums Victoria's proposed policy structure.

\begin{tabular}{cll}
\hline \multirow{2}{*}{ Minor revision } & $\bullet$ & Collection Care and Preservation \\
& $\bullet$ & Collection Deaccession \\
& $\bullet$ & Repatriation of Indigenous Cultural Property \\
\hline \multirow{2}{*}{ Substantial revision } & $\bullet$ & Collection Access, Loans and Use \\
\hline New & $\bullet$ & Collection Development \\
\hline & $\bullet$ & Collection Provenance and Legal Title Enquiries and Claims \\
\hline
\end{tabular}

\subsection{Challenges and Opportunities}

Meetings were robust. Previous processes were questioned, definitions contested, anxieties set in. Some staff were concerned that we would drown in paperwork unnecessarily and that community and government stakeholders would disengage. We had to be careful not to disparage what we had done in the-in fact, we already did most of what was listed in the Guide but what was clear was that we did not document decisions systematically or in a timely manner.

The Collections and Community Consultation Procedure was challenging. It was the first time MV had overtly considered community consultation in relation to all aspects of collection development and use. A lot of previous work was informal and often 'hidden' in curatorial files-so, not straightforward to locate and access. We have a Community Engagement Framework, endorsed by the Board in April 2009 and an established Community Engagement Reference Committee with a focus on community engagement and participation in public program activities, but not collection development and use. The ECLC working group referred to Appendix 3 of the Scheme Guidelines-Guidance [9] on consultation processes to develop the Collections and Community Consultation Procedure. This appendix provides a comprehensive set of points to consider when consulting with individuals, groups or communities. We were mindful of respecting existing relationships and wanted to create a two-way dialogue rather than just seek data for our use.

Early into our review we recognised that we would not always have the necessary curatorial expertise on staff to assist with due diligence and provenance research. We spoke with the exhibition team and agreed that designated roles within their team such as Producers and Exhibition Project Management staff would be responsible for ensuring MV undertakes the tasks to ensure compliance with the Scheme and that they needed to reflect such arrangements in contracts with lenders. This means that at the earliest possible stage of each internally-developed exhibition they must speak to the collection Department Head to undertake and/or facilitate preliminary research to complete the Provenance Risk Checklist for all items proposed for borrowing. If MV does not have an in-house Curator and/or Collection Manager, they must appoint an external expert.

Successful approval with the Scheme also requires demonstration of the competency of staff to enact the policies and procedures. A number of key staff undertook 'train the trainer' training with an external provider. We have drafted five basic training presentations for in-house courses to be presented in the 2019-2020 financial year, which we hope to maintain with refresher courses offered as changes and projects provide us with new learnings. At this point, I should add that MV has invested a substantial amount of financial resources and time in supporting staff to complete the Diploma in Law and Collections Management intensive and refresher courses run by the Institute of Art $\mathcal{E}$ Law. MV staff and colleagues from Australia and internationally will forever be indebted to the seemingly endless knowledge and enthusiastic delivery of such by the late law professor and barrister Professor Norman Palmer QC CBE, with Ruth Redmond-Parker by his side. We miss his wise counsel.

We discussed the changes to process and responsibilities with the Collection Information Systems team and sought a modest budget to modify the database. These modifications will allow staff to associate all evidence, sought and obtained in seeking due diligence and provenance, to be stored in the content management system MV Records (Hewlett Packard Enterprise) and linked to the collection 
management system EMu (Axiell ALM). We also hope to introduce other improvements to track specific tasks within EMu.

In summary, we have made the following improvements:

- $\quad$ standardised acquisition definitions and processes

- $\quad$ standardised the Deed of Gift (for donations)

- standardised the collection acquisition and collection deaccession forms

- developed a provenance risk ${ }^{1}$ checklist and rating matrix (see Tables 2 and 3) and a list of examples of high-risk categories of collection items

- developed a standard phrase regarding our commitment to due diligence and provenance for inclusion in agreements/contracts with lenders

- updated the Collection Development Committee terms of reference

- re-formed the long defunct Loans Committee with a new terms of reference and matched, to a degree, the delegations with those in the Collection Development Committee terms of reference

- $\quad$ successfully encouraged science staff to attach fieldwork licenses and permits to the database in order to validate specimens collected in the field.

Table 2. The checklist to assess the risk that the item(s) in question may have been obtained unethically or illegally, and/or that the item may be subject to third party claims. Staff tick all statements that apply.

\begin{tabular}{l}
\hline \multicolumn{1}{c}{ Risk Factor } \\
\hline 2.1 The item is considered high risk if any of the following factors apply: \\
\hline Item falls into high-risk category (see 3 Examples of High-Risk Categories of Collection Items) \\
\hline Evidence the item was not collected ethically, where collected after 1970. \\
\hline Documented reputational doubts regarding any party involved in the proposed transaction. \\
\hline There are known disputes relating to ownership. \\
\hline Ongoing conflict regarding ownership can reasonably be expected - from individuals, communities or \\
political/ideological groups. \\
\hline Potential conflicts of interest on the part of any party, including Museums Victoria. \\
\hline 2.2 The item is considered medium risk if any of the following factors apply, and none of the factors \\
in 2.1 apply: \\
\hline Provenance is incomplete - there are significant gaps in record of ownership. \\
Note: refer to departmental guidelines as to what gaps are considered 'significant'. For example, gaps \\
may exist for a significant type of information or for a particular period of time (e.g., a conflict period). \\
\hline Suspicion or evidence the item was not collected ethically, where collected prior to 1970. \\
\hline Identity of current legal owner unknown, unclear or unavailable. \\
\hline Appropriate collecting documentation or export permits are not available. \\
\hline 2.3 The item is considered low (or no) risk if any of the following factors apply, and none of the \\
factors in 2.1 or 2.2 apply: \\
\hline Full provenance is traceable. \\
\hline The correct collecting or export permits have been obtained or are available. \\
\hline Item is non-rare and/or mass-produced (e.g., commercial goods). \\
\hline Seller, agent, or lender holds legal title to the item and/or legal authority to lend. \\
\hline 2.4 Overall risk rating (high, medium or low): \\
\hline
\end{tabular}

1 The provenance risk checklist is a tool or prompt to assist staff to think about and identify provenance issues that may affect whether MV wants to acquire or lend collection material and is incorporated into the ethical and legal collecting policy and procedural framework. 
Table 3. Once the risk factors have been considered the provenance risk rating provides the next step.

\begin{tabular}{|c|c|}
\hline Risk Rating & What Next? \\
\hline Low & $\begin{array}{l}\text { Acquisitions: applications can proceed at a departmental level, as per regular procedures. } \\
\text { Use the Provenance Investigation Form to document any provenance research. } \\
\text { Loans: require approval by Department Heads. } \\
\text { Deaccessions: all proposals must be sent to the Collection Development Committee for } \\
\text { recommendation to the Museums Board of Victoria, regardless of their risk rating. }\end{array}$ \\
\hline Medium & $\begin{array}{l}\text { Acquisitions and deaccessions: proposals must be submitted to the Collection Development } \\
\text { Committee for review and recommendation, with a completed Provenance Investigation Form. } \\
\text { Loans: require approval by Department Heads, the Loans Committee and the Director, } \\
\text { Research and Exhibitions. } \\
\text { Any of these parties may also choose to refer items to the Chief Executive Officer and the } \\
\text { Museums Board of Victoria. }\end{array}$ \\
\hline High & $\begin{array}{l}\text { As for medium, but proposals will also need to be reviewed and assessed by the Chief } \\
\text { Executive Officer and the Museums Board of Victoria before they can proceed. }\end{array}$ \\
\hline
\end{tabular}

We did all of this during a period of great institutional transformation. Our executive structure, including the Chief Executive Officer, had recently changed and we commenced work on the $M V$ Strategic Plan 2017-25. There was a flurry of activity to reinvigorate the organisation which resulted in a delay in developing a specific procedure relating to research loans, standardising all forms and templates (for example, the object receipt form), or to rolling-out the training ahead of submitting our application.

On 29 March 2017, a little over a year after the first ECLC meeting, the newly appointed Chief Executive Officer, Lynley Marshall signed the Certification page of the application and I pressed 'send'.

The Hon Mitch Fifield, Minister for the Arts, approved the Museums Board of Victoria (trading as Museums Victoria) as an approved borrowing institution as of 26 June 2017. Additionally, our name was soon included in the list of approved institutions (see Table 4).

Table 4. Approved borrowing institutions and their period of approval.

\begin{tabular}{cc}
\hline Name of Institution & Date of Approval \\
\hline National Gallery of Victoria & 19 May 2015 to 18 May 2020 \\
National Museum of Australia & 19 August 2015 to 18 August 2020 \\
Western Australia Museum & 23 November 2015 to 22 November 2020 \\
Art Gallery of New South Wales & 29 March 2016 to 28 March 2021 \\
South Australian Museum & 24 August 2016 to 23 August 2021 \\
Museum of Applied Arts and Sciences & 24 August 2016 to 23 August 2021 \\
Queensland Museums & 2 December 2016 to 1 December 2021 \\
Museums Victoria & 26 June 2017 to 25 June 2022 \\
Australian Museum & 11 August 2017 to 10 August 2022 \\
Queensland Gallery and Gallery of Modern Art & 13 August 2017 to 12 August 2022 \\
National Gallery of Australia & 28 February 2018 to 27 February 2023 \\
National Library of Australia & 27 April 2018 to 26 April 2023 \\
\hline
\end{tabular}

\subsection{Learnings}

Our first use of the new and revised policies and procedures was for the incoming touring exhibition Vikings: Beyond the Legend (Melbourne Museum, 23 March to 26 August 2018) from the Swedish History Museum. The exhibition had just over 450 items. We engaged an external expert to undertake the due diligence and provenance requirements. This was organised by the exhibition team in consultation with the collection Department Head because we did not have the expertise on staff. We supplied the external expert with the paperwork, highlighted the requirements and provided her with the proposed items. She was able to source (and translate) a lot authoritative information, mostly available online. Most of these items had already been exhibited elsewhere and most of the items 
were the result of State-sanctioned archaeological surveys. She was candid in letting us know that the Provenance Risk Checklist was confusing (see Figure 1) and we subsequently reworked the checklist. Due to the nature of the exhibition, nearly all of the items had been excavated from grave sites and so the risk rating we had developed classified them all initially as high risk. We revised this as well expressed that our real concern in this area was Indigenous archaeological remains, rather than ancient. The expert also suggested arranging the information for publishing into groups of 'Artefacts, low risk', 'Artefacts, medium risk', and 'Artefacts and Human remains, high risk'. The items arrived safely and were displayed without claim or damage.

MV curated the exhibition My Life: The Official Exhibition (Melbourne Museum, 22 September 2018 to 3 March 2019) and in this instance we appointed in-house staff to undertake the due diligence and provenance requirements. Staff visited the items proposed for loan at the Nelson Mandela Foundation in Johannesburg and with a private overseas collector. A seemingly endless trail of emails and conversations took place to establish and clarify ownership and copyright and to form narratives. The items for loan included a rich selection of rare personal items, film footage and documents and were published on the MV website prior to their arrival in Australia, as per the requirement. Many of the items were on display outside of South Africa for the first time and Melbourne Museum was the first and only Australian venue as part of the proposed touring schedule. The in-house staff made connections with the local South African community, many of whom engaged with and promoted the exhibition.

The Loans Committee continues to meet. As per the procedure all outward and inward loans for exhibition and research are assessed and assigned a risk category. The majority are low risk. We continue to discuss the efficiency and benefit of assessing and reporting the science specimens we are lending given that most of the specimens have been acquired by MV staff on fieldwork and we hope to develop a more efficient methodology to track research loans across all collections.

In terms of acquisition and deaccession we have had several opportunities to use the Provenance Risk Checklist for initial assessment and the Provenance Investigation Form to document provenance research. Due to the lack of training we have had a lot of questions from curatorial staff and many discussions (still) about why we have implemented the process. We rarely buy collection items; the majority of our acquisitions are donated or collected in the field with the relevant licence or permit. However, we recently purchased and exported minerals from China and Pakistan. These specimens are of relatively low monetary value, but this does not mean they require less scrutiny. Provenance research confirmed these specimens are minerals available in the world-wide dealer market, were sourced through legitimate local mineral dealers in China and Pakistan and cleared with local export of the respective countries, as well as Australian customs and quarantine authorities.1.3.

What next? We have assigned the development of the Managing Inward and Outward Loans for Research Loans Procedure to a small working group and hope to complete this by 2020 . This procedure will take into the account the Nagoya Protocol and will require a review of the MV Animal Ethics handbook, as well as an application form template and agreement template.

We will adjust the drafted training modules (see Figure 1) and have identified the relevant internal stakeholders. We will add these modules to MV's learning system and calendar and invite staff to enrol. Members of the ECLC working group will deliver these modules. 


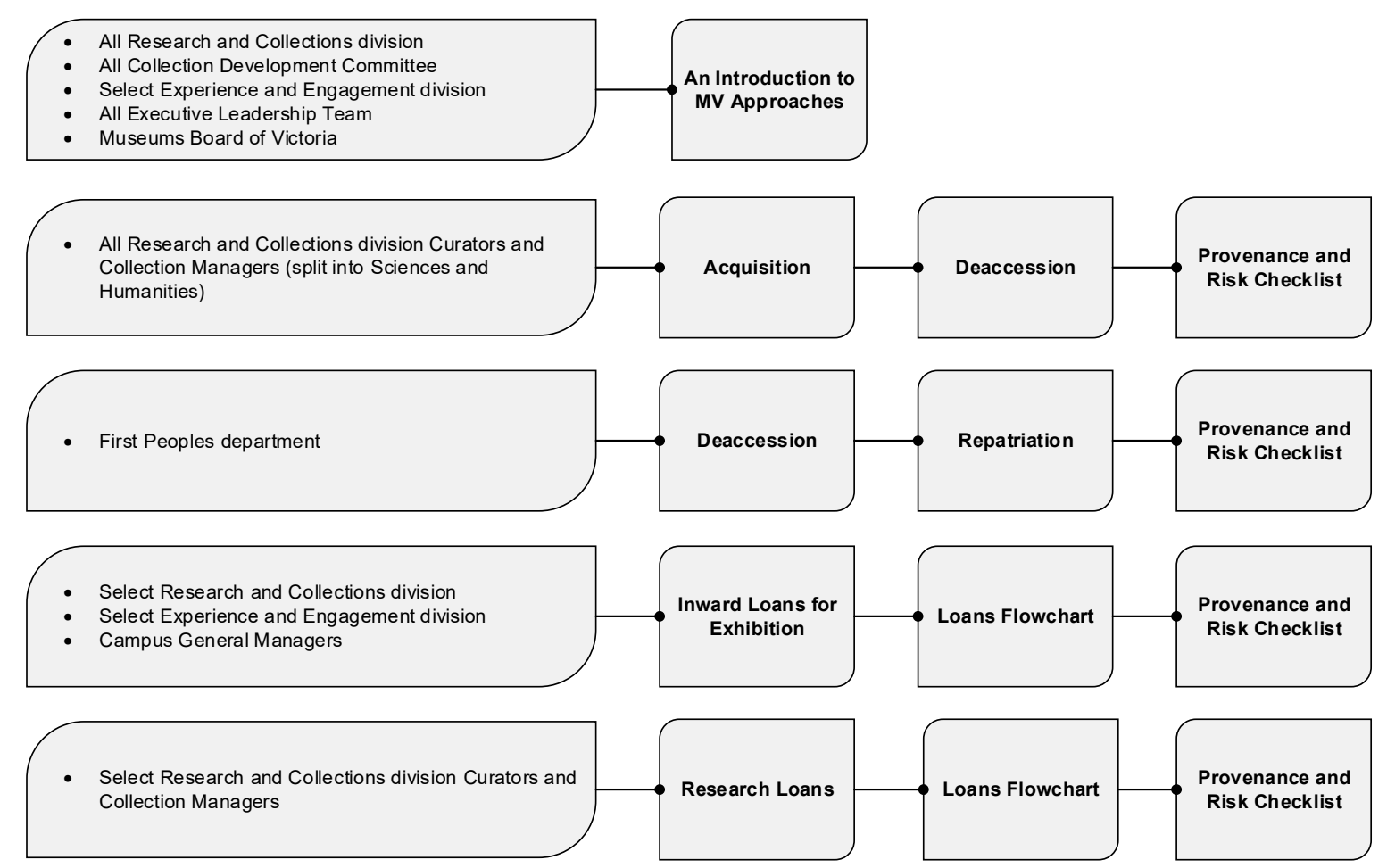

Figure 1. Training modules and primary stakeholders.

I would also like to (re)start or join a discussion about developing templates for sharing data between lenders and borrowers across the cultural sector. Too often we receive and send lists in formats that are inaccessible by colleagues. They often require considerable reworking in order to assess items for borrowing or lending, which detracts from the more important tasks of due diligence and provenance research. Thumbnails embedded in a PDF are a nightmare and often the only image we have to work with in terms of identifying an item from afar and for publishing online prior to export. The ICOM Object ID Checklist provides a great starting point for 'objects' [10] and could be improved with the addition of natural science-related information.

We will continue to monitor all of our activities, policies, procedures, and associated documents and update them as relevant.

Funding: This research received no external funding.

Conflicts of Interest: The author declares no conflict of interest.

\section{References}

1. UK Museums up in Arms over Art Grab. 2004. Available online: http:/ /www.abc.net.au/news/2004-07-26/ uk-museums-up-in-arms-over-art-grab / 2015664 (accessed on 18 July 2018).

2. Museums Board of Victoria v Carter; No. 645; Federal Court of Australia: Sydney, Australia, 2005.

3. UNESCO World Heritage Centre. Royal Exhibition Building and Carlton Gardens. Available online: http:/ / whc.unesco.org/en/list/1131/ (accessed on 18 July 2018).

4. Protection of Cultural Objects on Loan Regulation. 2014. Available online: http:/ /www.legislation.gov.au/ Details/F2014L01329/ExplanatoryStatement/Text (accessed on 18 July 2018).

5. Department of the Prime Minister and Cabinet Office for the Arts. Immunity from Seizure for Cultural Objects on Loan Discussion Paper 2011, 21 June 2011.

6. Council of Australasian Museum Directors (CAMD). Response to the Department of the Prime Minister and Cabinet Office for the Arts Immunity from Seizure for Cultural Objects on Loan Discussion Paper. 2011. Available online: https:/ / camd.org.au/files/2012/03/CAMD-Response-to-Commw-Discussion-Paper-onImmunity-from-Seizure-August-2011.pdf (accessed on 18 July 2018). 
7. Protection of Cultural Objects on Loan Bill 2012. Available online: https:/ / parlinfo.aph.gov.au/parlInfo/ download/legislation/billsdgs/2211701/upload_binary/2211701.pdf;fileType=application/pdf (accessed on 13 March 2019).

8. Department of Communications and the Arts. Guidance for Lenders_Protection of Cultural Objects on Loan, 21 August 2017.

9. Department of Communications and the Arts "Scheme Guidelines". 2015. Available online: https:/ /www. arts.gov.au/sites/g/files/net1761/f/protection-of-cultural-objects-on-loan-scheme-guidelines-pro.pdf (accessed on 19 July 2018).

10. Object ID: An International Standard for Describing Art. Available online: http:/ / archives.icom.museum/ object-id/ (accessed on 25 July 2018).

2019 by the author. Licensee MDPI, Basel, Switzerland. This article is an open access article distributed under the terms and conditions of the Creative Commons Attribution (CC BY) license (http://creativecommons.org/licenses/by/4.0/). 